\title{
Catalytic Activation of All-Silica COK-14 Zeolite through Alumination and Particle Size Reduction using Wet Ball Milling
}

Michiel De Prins ${ }^{\mathrm{a}}$, Elke Verheyen ${ }^{\mathrm{a}}$, Gina Vanbutsele ${ }^{\mathrm{a}}$, Sreeprasanth Pulinthanathu Sree ${ }^{\mathrm{a}}$, Karine Thomas $^{\mathrm{b}}$, Jean-Pierre Gilson ${ }^{\mathrm{b}}$, Jozef Vleugels ${ }^{\mathrm{c}}$, Christine E.A. Kirschhock ${ }^{\mathrm{a}}$ and Johan A. Martens*a

${ }^{a}$ Centre for Surface Chemistry and Catalysis, University of Leuven, Celestijnenlaan 200f, Leuven, 3001, Belgium.

E-mail: johan.martens@kuleuven.be

${ }^{\mathrm{b}}$ Laboratoire Catalyse \& Spectrochimie (LCS), ENSICAEN, 6 boulevard Mare'chal Juin, Caen, 14050, France

${ }^{\mathrm{c}}$ Department of Materials Engineering, University of Leuven, Kasteelpark Arenberg 44, Leuven, 3001, Belgium

Declarations of interest: none

Key words: Zeolite, COK-14, OKO, Wet ball milling, Multidirectional Turbula shaker-mixer, n-decane hydroconversion,

\section{Highlights:}

- Wet ball milling of -COK-14 zeolite in presence of a dissolved Al source.

- Particle size reduction and framework aluminum introduction result from milling.

- Milled and aluminated COK-14 contains Brønsted acid sites.

- Milled and aluminated COK-14 loaded with platina is an ideal bifunctional catalyst.

\begin{abstract}
The precursor of all-silica COK-14 zeolite (OKO topology) with interrupted framework was subjected to wet ball milling in the presence of aluminum isopropoxide. Alumination and particle size reduction of the zeolite crystals was combined in this way Wet ball milling resulted in fragmentation of the platelet-shape COK-14 crystals while preserving crystallinity. ${ }^{27} \mathrm{Al}$ NMR spectroscopy of the fully condensed COK-14 zeolite, obtained by calcination of milled -COK-14 precursor, confirmed the incorporation of tetrahedrally coordinated $\mathrm{Al}$ atoms in the framework. The creation of Brønsted acid
\end{abstract}


sites was confirmed by pyridine adsorption. Loaded with platinum, the sample showed ideal bifunctional catalytic behavior in hydroisomerization and hydrocracking of n-decane model alkane compound. Aluminum incorporation by milling is an alternative to the atomic layer deposition (ALD) process using trimethylaluminum and to thermal alumination. Wet ball milling in presence of aluminum isopropoxide shows great potential for making siliceous zeolites catalytically active.

\section{Introduction}

Zeolites with all-silica framework have peculiar properties. They are suited for adsorption and molecular separation as their intrinsic hydrophobic nature enables preferential adsorption of organic molecules [1]. Siliceous zeolites are of interest to energy applications as they show spring, shock-absorber or bumper behavior in high pressure water and electrolyte intrusion-extrusion cycles [2] and their very low dielectric constant is of interest in microelectronics fabrication technology [3]. But catalysis is one of the largest application fields of zeolites. The annual production exceeds 1 million ton [4]. Most of the zeolites applied in industrial catalysis either have pores formed by 10-membered rings (10-MRs) or 12membered rings (12-MRs) of framework tetrahedra [4]. Zeolites which combine 10-MRs and 12-MRs are particularly of interest [5]. At this moment of writing, there are 18 framework topologies that combine these two ring sizes [6]. The zeolite of this study (COK-14 with OKO topology) has 10-MRs and 12-MRs channels in a 2-dimensional intersecting channel system. The crystals have platelet morphology and, unfortunately, the two types of channels run according to the long dimensions of the platelets such that only the edges of the platelets are provided with openings of the pore system. Fragmentation of the particles is an obvious way to enhance the accessibility of the pore system to guest molecules for catalysis. This raises interest in techniques such as ball milling.

Ball milling has been mentioned in catalysis literature since the 1980's [7]. It is often mentioned together with mechanochemistry, referring to chemical changes caused by mechanical treatment [8-11]. Ball milling has been used to prepare catalysts both during synthesis, referred to as mechanochemical synthesis, and post synthesis, referred to as mechanochemical activation [11]. Some catalysts prepared via milling proved to be more active than conventionally prepared catalysts [8,12]. One reason for this is the increase in number of pore openings and the shortening of the length of the pores via particle size reduction. This reduces the intragranular mass transport limitation of catalytic processes [13]. In some cases, structural defects are introduced or altered [8] and a change of oxidation state of transition metals can occur [9-11].

Milling operations can be divided in wet and dry milling. Wet milling has advantages over dry milling, such as a higher energy efficiency, better heat dissipation and absence of dust formation [14]. Milling operations can substitute other types of unit operations and minimize the use of solvents [8]. In this regard, milling operations to alter materials chemistry can be categorized as green chemistry $[15,16]$. 
Zeolites are fragile materials undergoing amorphization during dry ball milling $[14,15,17,18]$. In some instances, a partially amorphizised zeolite shows enhanced selectivity by the alteration of the acid-base properties [19]. Zeolite A particle size reduction from micron to nanoscale through milling, followed by a repair of damaged parts by recrystallization in diluted aluminosilicate solution has been reported [20]. Similar recrystallization after a milling process has also been reported for other frameworks [13]. The crystallinity of a zeolite is better maintained using wet ball milling [21]. Many types of mills are available. Planetary ball milling is most often mentioned in literature dealing with zeolite milling [2225].

Incorporation of trivalent aluminum atoms in the silicate framework of a zeolite creates cation exchange capacity and Brønsted acid sites when framework charges are compensated with protons. All-silica COK-14 is prone to such modification. Atomic layer deposition (ALD) of aluminum has been used to incorporate aluminum into zeolites and siliceous nanoporous powders [26,27]. An earlier study already showed ALD to an effective means for the alumination of COK-14 [28].

In this paper, we explore the possibility of combining alumination and crystal fragmentation by wet ball milling in presence of aluminum isopropoxide solution. The success of the modification in view of catalytic activity is evaluated via the hydroisomerization and hydrocracking reactions of n-decane. $n$ Decane was used as model molecule as it represents an ideal probe reaction for evaluation of the catalytic activity [29-32] and the manifestation of molecular shape selectivity [33,34]. The catalytic activation of COK-14 zeolite by the milling process is compared to the ALD method and thermal procedures, which are proven techniques [28-30].

\section{Experimental}

\subsection{Materials}

Zeolite synthesis: COK-14 was synthesized as described in literature via a transformation of IM-12 (UTL topology) to -COK-14, followed by a calcination to obtain COK-14 [37]. The precursor IM-12 zeolite was synthesized using (6R,10S)-6,10-dimethyl-5 azoniaspiro [4,5] decane hydroxide as structure directing agent (SDA). The gel had a molar composition according to the following ratios: $0.8 \mathrm{SiO}_{2}$ $0.4 \mathrm{GeO}_{2}-0.2 \mathrm{SDA}-30 \mathrm{H}_{2} \mathrm{O}$. Details of the synthesis recipe of IM-12 have been published elsewhere [38]. The SDA was removed from the structure by heating to $550{ }^{\circ} \mathrm{C}$ in air with a temperature ramp of $1{ }^{\circ} \mathrm{C} / \mathrm{min}$. This temperature was maintained for $8 \mathrm{~h}$ before cooling. The conversion of IM- 12 to an intermediate structure labeled -COK-14, with a hyphen referring to the systematically interrupted framework, was obtained by slurrying the thermally treated IM-12 zeolite in $12 \mathrm{M} \mathrm{HCl}$ solution (VWR Chemicals) in a polypropylene bottle in proportions of $50 \mathrm{~g} \mathrm{HCl}$ solution for $1 \mathrm{~g}$ of IM-12 at $95{ }^{\circ} \mathrm{C}$ for $48 \mathrm{~h}$. The zeolite was recovered via filtration, rinsed with distilled water and dried at $60^{\circ} \mathrm{C}$. This material 


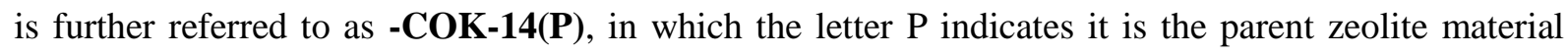
obtained by IM-12 transformation.

Ball milling: An initial wet ball milling experiment in the absence of an aluminum compound was performed to determine the most optimal milling parameters with respect to particle size and morphology. This experiment took place at room temperature in $100 \mathrm{~mL}$ polypropylene flasks on a multidirectional shaker-mixer (Turbula type T2C, WAB, Switzerland) operating at $35 \mathrm{rpm}$. The Turbula works according to Schatz's geometric theory, combining rotation, translation and inversion into a three dimensional movement that is optimal for achieving homogeneous powders rapidly [39]. The flasks were filled with $500 \mathrm{mg}$ zeolite, $50 \mathrm{~g}$ of milling balls, and ca. $40 \mathrm{~mL}$ solvent (ethanol or isopropanol, VWR Chemicals). The milling balls with $2 \mathrm{~mm}$ or $5 \mathrm{~mm}$ diameter were made of zirconia (Grade TZ$3 \mathrm{Y}$, Tosoh, Japan). Samples were taken at regular time intervals. After milling, the milling balls were recovered via sieving. The zeolite was separated from the resulting solution by centrifugation at 2,300 rpm for $8 \mathrm{~min}$. The milled zeolite was rinsed twice by slurrying it in ethanol or isopropanol, depending on which of these solvent was used in the milling, and recovered by centrifugation under the mentioned conditions. Finally the zeolite was dried overnight in an oven at $60{ }^{\circ} \mathrm{C}$ and stored.

Alumination via wet ball milling was performed similarly to the initial wet ball milling experiment. $200 \mathrm{mg}$ of aluminum isopropoxide (Acros Organics) was added to $40 \mathrm{~mL}$ isopropanol before mixing with $500 \mathrm{mg}$ zeolite. Zirconia milling balls with a diameter of $2 \mathrm{~mm}$ and a milling time of 1 hour were chosen for this experiment. After milling, powder was recovered as described for the initial milling experiment. The ammonium exchanged form was obtained by suspending the milled aluminated zeolite powder in a $0.5 \mathrm{M} \mathrm{NH}_{4} \mathrm{Cl}$ (MP Biomedicals LLC) solution at a ratio of $100 \mathrm{~mL}$ solution per $1 \mathrm{~g}$ of zeolite and heated under reflux for 90 minutes. Afterwards, the zeolite was recovered from the liquid in a centrifuge turning at 2,300 rpm for $8 \mathrm{~min}$, followed by three rinsing steps with water, each followed by centrifugation. The obtained zeolite was dried overnight at $60^{\circ} \mathrm{C}$. This ammonium-exchanged aluminated milled material is referred to as -COK-14-Mil. After calcination at $400{ }^{\circ} \mathrm{C}$ for $8 \mathrm{~h}$ at a heating rate of $1{ }^{\circ} \mathrm{C} / \mathrm{min}$, the hyphen is omitted from the sample notation to indicate it is the condensed form, COK-14-Mil.

Thermal alumination: Aluminum was incorporated in -COK-14(P) material by a static treatment with an aqueous aluminum solution under thermal conditions. A $100 \mathrm{~mL}$ polypropylene flask was filled with $1 \mathrm{~g}$-COK-14(P), $0.4 \mathrm{~g}$ aluminum isopropoxide (Acros Organics) and $80 \mathrm{~mL}$ dried isopropanol (VWR Chemicals) and was left for $24 \mathrm{~h}$ in an oven at $90{ }^{\circ} \mathrm{C}$. Afterwards the samples were centrifuged for $7 \mathrm{~min}$ at 3,200 rpm after which the recovered powder was suspended again in isopropanol and centrifuged under the same conditions. This last step was repeated once more before drying the powder overnight in an oven at $60^{\circ} \mathrm{C}$. After ammonium exchange via the protocol explained for -COK-14-Mil, this 
material is referred to as -COK-14-Therm. The notation without hyphen refers to the calcined $\left(400{ }^{\circ} \mathrm{C}\right.$, $1{ }^{\circ} \mathrm{C} / \mathrm{min}, 8 \mathrm{~h}$ ) sample, with fully connected framework.

Al-ALD: The COK-14 sample aluminated via atomic layer deposition was reported earlier [28]. The sample was prepared in a custom built ALD set-up with a deposition chamber maintaining a base pressure of $10^{-4} \mathrm{~Pa}$ [40]. Inside the chamber a resistive heater was mounted on which an aluminum plate with a surface area of ca. $25 \mathrm{~cm}^{2}$ was placed. $200 \mathrm{mg}$ of -COK-14 was finely dispersed over this plate. In a first step, the sample was heated to $200{ }^{\circ} \mathrm{C}$ for $90 \mathrm{~min}$ in vacuum. In a second step, the sample was exposed to trimethylaluminum vapor at $0.3 \mathrm{~Pa}$ for $60 \mathrm{~s}$ followed by $120 \mathrm{~s}$ evacuation. Step three comprised exposure to $0.3 \mathrm{~Pa}$ of water vapor for $40 \mathrm{~s}$, followed by $120 \mathrm{~s}$ evacuation. Step two and three were performed 5 times. The resulting materials were exchanged to the ammonium form via the same procedure as described for -COK-14-Mil and -COK-14-Therm. After ammonium exchange, this material is referred to as -COK-14-ALD. The notation without hyphen refers to the calcined sample with fully connected framework.

Pt loading for bifunctional catalyst preparation: Pt loading was performed via incipient wetness impregnation: $0.1 \mathrm{~g}$ of each ammonium-exchanged zeolite powder was mixed in a $20 \mathrm{~mL}$ polypropylene container with $0.1 \mathrm{~g}$ of an aqueous solution of tetramineplatinum(II) chloride monohydrate (Alfa Aesar), to obtain a $0.5 \mathrm{wt} \%$ platinum loading on dry zeolite basis. The obtained wet powder was gently molded with a spatula to obtain a good homogeneity before placing the mixture in an oven at $60{ }^{\circ} \mathrm{C}$ to dry overnight.

\subsection{Physico-chemical characterization}

X-ray diffraction was performed on a STOE STADI MP diffractometer with $\mathrm{CuK}_{\alpha}$ radiation in highthroughput mode. High resolution SEM images were obtained using a Nova NanoSEM450 FEI instrument. The samples were prepared by applying a small amount of material on a carbon sticker. Surface area and pore volume were derived from $\mathrm{N}_{2}$ adsorption isotherms determined on a Quantachrome Autosorb-1 instrument. Prior to nitrogen adsorption, samples were evacuated at $120{ }^{\circ} \mathrm{C}$ for $12 \mathrm{~h}$. The specific surface area, external surface area and micropore volume were analyzed using the BET method and the t-plot method, respectively. Chemical analysis was performed using inductively coupled plasma optical emission spectrometry (ICP-OES) on a Varian 720 ES instrument. Aluminum incorporation was investigated using ${ }^{27} \mathrm{Al}$ MAS NMR with single pulse excitation under magnetic angle spinning (1D) on a Bruker Avance 400 instrument $\left(B_{o}=9.4 \mathrm{~T}\right)$ with a $2.5 \mathrm{~mm}$ MAS rotor. The presence of acid sites was evaluated by FTIR spectroscopy and pyridine adsorption. The infrared spectra were recorded using a Nicolet Nexus FTIR spectrometer. Samples were mounted in the FTIR cell and outgassed in vacuum $\left(210^{-6}\right.$ torr $)$ at $120^{\circ} \mathrm{C}$ and $400{ }^{\circ} \mathrm{C}$. All samples were saturated with 1 torr pyridine 
vapor at $120^{\circ} \mathrm{C}$. After equilibration, the samples were outgassed at $150{ }^{\circ} \mathrm{C}$ and $200{ }^{\circ} \mathrm{C}$ and the IR spectra

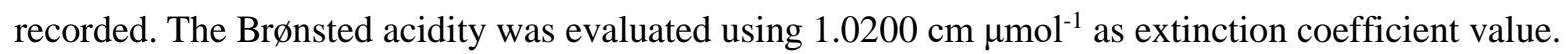

\section{3. n-Decane hydroisomerization and hydrocracking}

n-Decane hydroconversion was performed in a custom-made high-throughput 16 parallel tube reactor with inline reaction product analysis as described in literature [41-43]. A quartz reactor tube with internal diameter of $2.1 \mathrm{~mm}$ was loaded with $35 \mathrm{mg}$ of catalyst. In order to prevent pressure buildups and preferential flow paths, the catalyst was first compressed into flakes, crushed and sieved to obtain a particle size fraction of $150-250 \mu \mathrm{m}$. The catalyst was pretreated in the reactor at $400{ }^{\circ} \mathrm{C}$, reached by heating in oxygen gas at $5{ }^{\circ} \mathrm{C} / \mathrm{min}$. At $400{ }^{\circ} \mathrm{C}$, oxygen gas was fed for $1 \mathrm{~h}$, followed by 25 min of flushing with nitrogen gas, followed by $1 \mathrm{~h}$ of hydrogen gas exposure without intermittent cooling. During this pretreatment, the open -COK-14 samples transform in the closed COK-14 variants. The pretreatment is followed by cooling to the initial test temperature. The following reaction conditions were used: $\mathrm{PH}_{2} / \mathrm{PC}_{10}=214, \mathrm{~W} / \mathrm{F}_{0}=980 \mathrm{~kg} \mathrm{~s} \mathrm{~mol}^{-1}, \mathrm{P}=0.45 \mathrm{MPa}$. The reaction temperature was increased in steps of $5{ }^{\circ} \mathrm{C}$ starting at $150{ }^{\circ} \mathrm{C}$. Reaction products were sampled for inline gas chromatographic (GC) analysis every time the catalyst had been operating at the reaction temperature set point for one hour. The GC was equipped with a non-polar column (BP-1 $50 \mathrm{~m} \times 0.32 \mathrm{~mm} \times 1 \mu \mathrm{m}$ ) with a film of fused silica. Nitrogen was used as carrier gas for the GC analysis. The absence of catalyst deactivation was verified by returning to the initial reaction conditions at the end of the run.

\section{Results and discussion}

COK-14 and -COK-14 zeolite crystals can be considered to consist of layers. The leaching of germanium from the parent UTL zeolite in $12 \mathrm{M} \mathrm{HCl}$ leads to a systematically interrupted framework denoted -COK-14 [38]. The interruption splits the zeolite into layers. Heating of the obtained allsilica -COK-14 in absence of water or moisture, results in fully connected COK-14 zeolite by reorientation and condensation of silanol groups of the layers [28,37,44]. Upon adsorption of water, even under ambient conditions, the fully condensed framework is locally hydrolyzed again at the same positions. The interrupted -COK-14 framework with high silanol content was expected to be more reactive towards alumination compared to the fully condensed form. For this reason the milling process was performed on the open -COK-14(P) rather than closed COK-14(P).

SEM images of -COK-14(P) confirm the typical platelet morphology with mostly straight, smooth edges. (figure $1 \mathrm{a}$ ). The platelets of -COK-14(P) measure roughly $5 \mu \mathrm{m}$ x $5 \mu \mathrm{m}$ x $100 \mathrm{~nm}$. After milling for 15 minutes with $5 \mathrm{~mm}$ balls in presence of ethanol without aluminum (figure $1 \mathrm{~b}$ ) the particle edges were roughened and the shape resembled the pieces of a jigsaw puzzle. The platelets also displayed perforation. Continuing the milling for an additional $1 \mathrm{~h}$ led to fragmentation (figure $1 \mathrm{c}$ ). XRD confirmed that there was no loss of crystallinity up to this point. Milling for $24 \mathrm{~h}$ resulted in the presence 
of small pieces of material either clustered together or located on the sides of other platelets (figure 1 d). This seems to be debris formed during the breaking of the zeolite particles. Even after $24 \mathrm{~h}$ of wet ball milling in these gentle conditions, XRD still did not show a loss in crystallinity of the material. As expected, most of the size reduction happens early on during the milling. The formation of fines is to be avoided because it complicates the handling of the sample. The use of smaller balls with a $2 \mathrm{~mm}$ diameter resulted in similar milling behavior, but the fragmentation process was accelerated and less holes were created in the platelets. Later wet milling experiments were therefore performed using $2 \mathrm{~mm}$ balls. The milling time needed for obtaining significant fragmentation, without formation of fines, was established to be $1 \mathrm{~h}$.

Subsequently, -COK-14(P) was wet ball milled for $1 \mathrm{~h}$ in presence of aluminum isopropoxide. The SEM images (figure $1 \mathrm{e}, \mathrm{f}$ ) show that this resulted in an alteration of the particle size and morphology similar to the milling in the absence of the aluminum source (figure $1 \mathrm{~d}$ ). The original typical dimensions of the parent material of ca. $5 \mu \mathrm{m}$ x $5 \mu \mathrm{m}$ x $0.1 \mu \mathrm{m}$ were reduced to ca. $3 \mu \mathrm{m}$ x $3 \mu \mathrm{m} \times 0.1 \mu \mathrm{m}$. Milling did not affect the thickness of the platelets but the impact of the milling balls lead to breakage of the platelets in smaller pieces. According to XRD, the zeolite remained crystalline (figure 2).
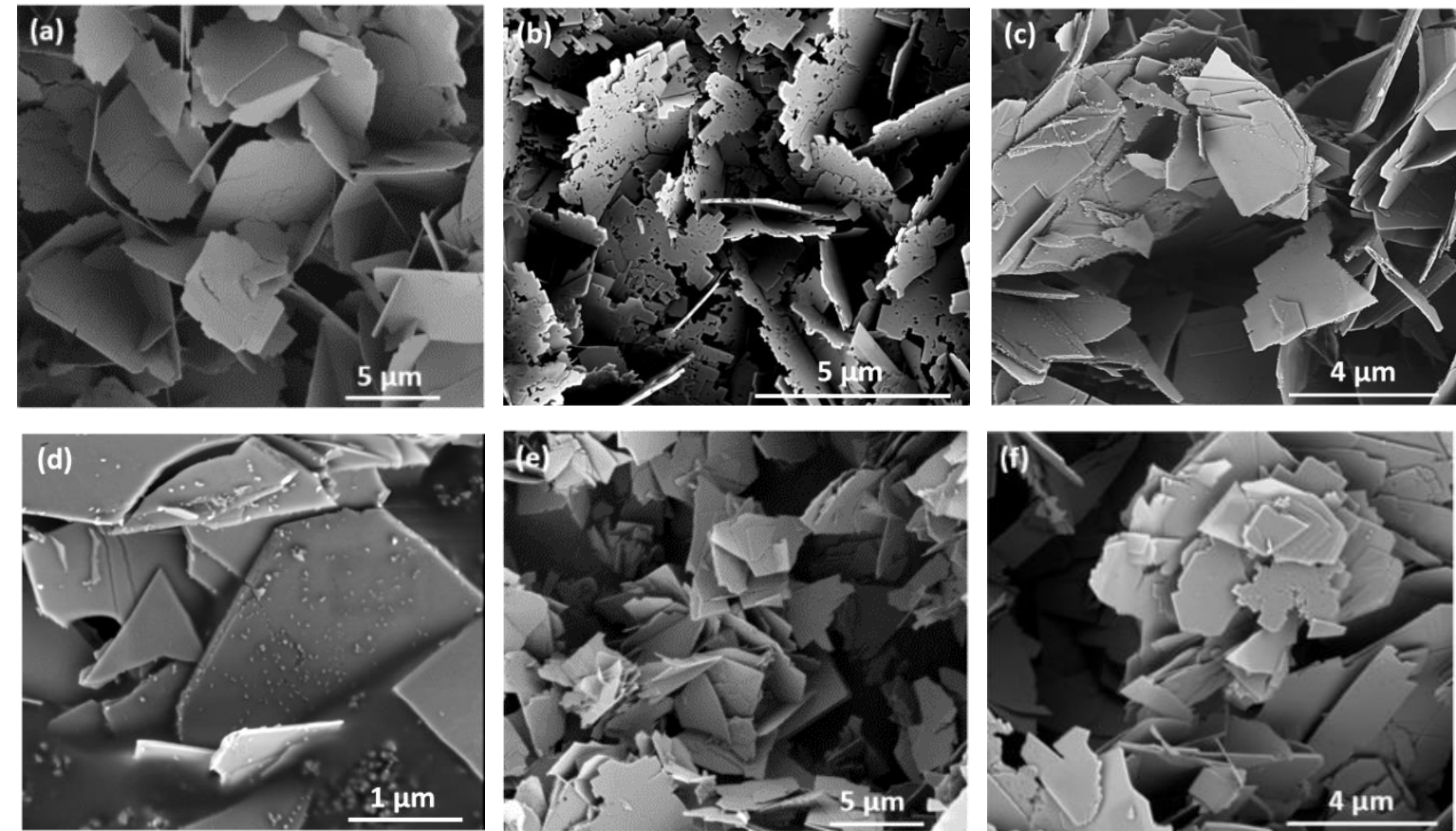

Figure 1: SEM images of: -COK-14(P) (a); -COK-14(P) milled in isopropanol in the absence of aluminum with $5 \mathrm{~mm}$ balls for $15 \mathrm{~min}$ (b), for $1 \mathrm{~h}$ (c) and for $24 \mathrm{~h}$ (d); -COK-14-Mil, which used $2 \mathrm{~mm}$ balls (e and f). 


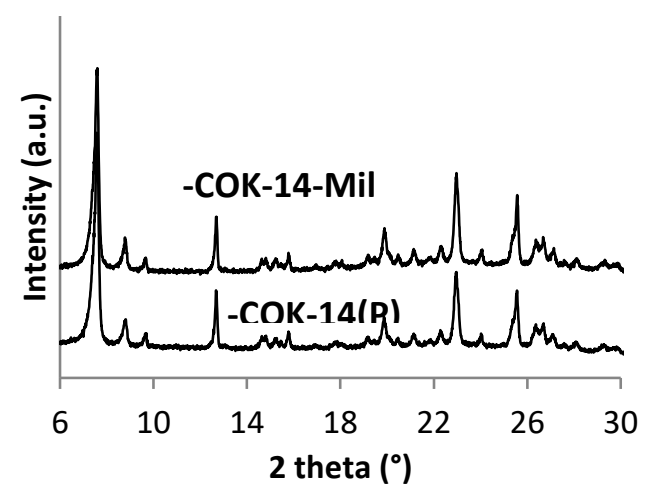

Figure 2: XRD pattern of -COK-14(P) and -COK-14-Mil.

The successful alumination of -COK-14-Mil was confirmed by chemical analysis and ${ }^{27} \mathrm{Al}$ MAS NMR. The $\mathrm{Al}$ content of the ammonium exchanged, closed COK-14-Mil sample amounted to $1.6 \mathrm{wt} \%$ (table 1). The aluminum speciation of COK-14-Mil determined with ${ }^{27} \mathrm{Al}$ MAS NMR obtained after closure of the framework by heating (figure 3, table 1) revealed the presence of framework aluminum with chemical shift of ca. $55 \mathrm{ppm}$, distorted tetrahedral aluminum and pentacoordinated aluminum with a broad signal around $30 \mathrm{ppm}$, and octahedral extraframework aluminum detected at $0 \mathrm{ppm}$. Octahedral aluminum dominated $(77 \%)$ while the targeted framework aluminum represented $14 \%$ of the incorporated aluminum. Aluminum with NMR resonance at $30 \mathrm{ppm}$, assigned to distorted tetrahedral and pentacoordinated Al, could also be part of the framework.

Table 1: Total aluminum content determined by ICP-OES analysis and aluminum distribution determined via ${ }^{27} \mathrm{Al}$ MAS NMR.

\begin{tabular}{|c|c|c|c|}
\hline Sample & COK-14-Mil & COK-14-Therm & COK-14-ALD * \\
\hline Total Al (wt\%) & 1.6 & 3.1 & 1.6 \\
\hline $\mathrm{Al}(\mathrm{IV})(\%)$ & 14 & 12 & 21 \\
\hline $\mathrm{Al}\left(\mathrm{IV}_{\mathrm{D}}\right)+(\mathrm{V})(\%)$ & 9 & 7 & 19 \\
\hline $\mathrm{Al}(\mathrm{VI})(\%)$ & 77 & 80 & 60 \\
\hline
\end{tabular}

*data from ref. [28].

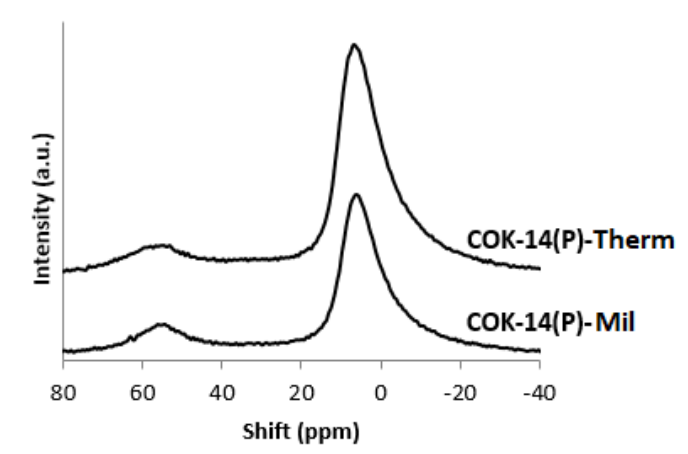

Figure 3: ${ }^{27} \mathrm{Al}$ NMR spectrum of COK-14-Mil and COK-14-Therm. 
The acidity of the ammonium-exchanged, calcined samples was investigated using pyridine adsorption and FTIR spectroscopy (table 2). The parent COK-14(P) all-silica zeolite has no acid sites, as expected. COK-14-Mil had $11 \mathrm{mmol} \mathrm{kg}^{-1}$ Brønsted acid sites (retaining pyridine at $150{ }^{\circ} \mathrm{C}$ ) of which $7 \mathrm{mmol} \mathrm{kg}^{-1}$ strong acid sites still retained pyridine at $200{ }^{\circ} \mathrm{C}$.

The presence of Brønsted acid sites is due to the introduction of aluminum in the framework. A Brønsted acid site concentration of $11 \mathrm{mmol} \mathrm{kg}^{-1}$ is fairly low. It corresponds to a $\mathrm{Si} / \mathrm{Al}$ ratio of $1,500 \mathrm{in}$ an idealized zeolite with all $\mathrm{Al}$ atoms in the framework. In previous work on ZSM-5 zeolites, however, it has been shown that a $\mathrm{Si} / \mathrm{Al}$ ratio of 1,000 is providing enough acidity to enable bifunctional catalysis [45].

Table 2: Concentration of Brønsted and Lewis acid sites probed with pyridine adsorption and FTIR spectroscopy.

\begin{tabular}{lccc}
\hline Sample & COK-14-Mil & COK-14-Therm & COK-14-ALD [28] \\
\hline Pyridine retained at $150{ }^{\circ} \mathrm{C}\left(\mathrm{mmol} \mathrm{kg}^{-1}\right)$ & 11 & 15 & 6.5 \\
Pyridine retained at $200{ }^{\circ} \mathrm{C}\left(\mathrm{mmol} \mathrm{kg}^{-1}\right)$ & 7 & 10 & 5 \\
\hline
\end{tabular}

The porosity of the samples was investigated using $\mathrm{N}_{2}$ adsorption isotherms (figure 4 , table 3 ). The nitrogen adsorption isotherms showed strong $\mathrm{N}_{2}$ uptake at low relative pressure, characteristic of zeolites. The milling process enhanced the BET specific surface area from $380 \mathrm{~m}^{2} \mathrm{~g}^{-1}$ to $447 \mathrm{~m}^{2} \mathrm{~g}^{-1}$, and the external specific surface area from $158 \mathrm{~m}^{2} \mathrm{~g}^{-1}$ to $184 \mathrm{~m}^{2} \mathrm{~g}^{-1}$. The micropore volume was enhanced from 0.109 to $0.128 \mathrm{~mL} \mathrm{~g}^{-1}$. The gain in surface area and porosity of COK-14-Mil through the milling process can be ascribed to fracturing of the zeolite particles, leading to an enhanced exposure of surface area and providing more access to micropores.

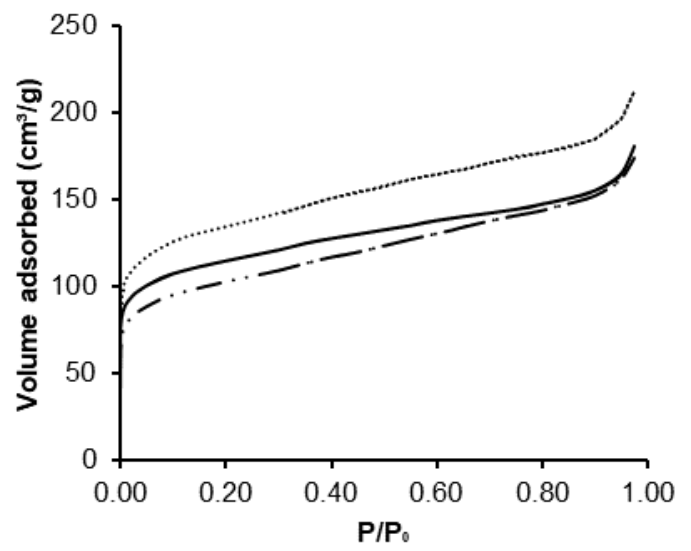

(a)

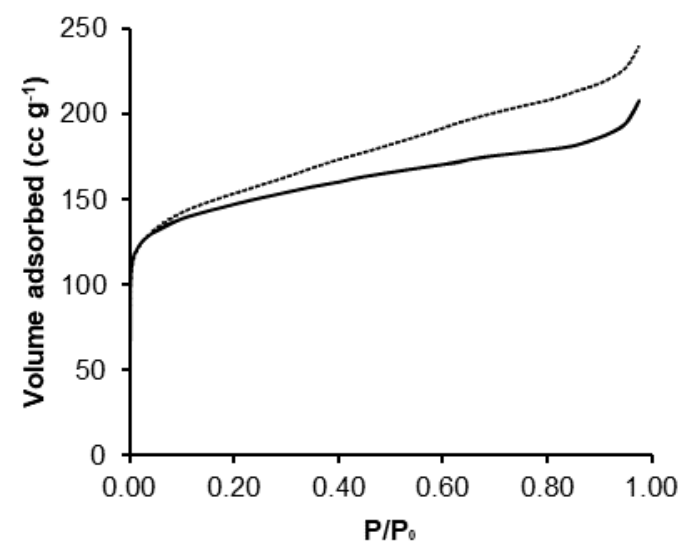

(b)

Figure 4: Nitrogen adsorption isotherms of a) COK-14(P) (continuous line), COK-14-Mil (dotted line), COK-14-Therm (dash-dotted line) and b) COK-14-ALD (dotted line) and before the ALD process (continuous line).

Table 3: Specific surface area and porosity according to $\mathbf{N}_{2}$ physisorption

\begin{tabular}{llllll}
\hline Sample & COK-14(P) & COK-14-Mil & COK-14- & COK- & COK-14- \\
& & Therm & 14(P) * & ALD \\
\hline BET $\left(\mathrm{m}^{2} \mathrm{~g}^{-1}\right)$ & 380 & 447 & 342 & 487 & 580
\end{tabular}




$\begin{array}{llllll}\text { Micropore volume }\left(\mathrm{mL} \mathrm{g}^{-1}\right) & 0.109 & 0.128 & 0.103 & 0.157 & 0.165 \\ \text { External surface area }\left(\mathrm{m}^{2} \mathrm{~g}^{-1}\right) & 158 & 184 & 133 & 161 & 256\end{array}$

* parent zeolite from previous work [28].

Wet ball milling was compared with a thermal alumination involving heating of the zeolite at $90{ }^{\circ} \mathrm{C}$ in the presence of aluminum isopropoxide solution in the same proportion as in the milling process, viz. zeolite : aluminum isopropoxide weight ratio of $0.4: 1.0$. Compared to milling, nearly twice as much aluminum was incorporated (table 1). The aluminum speciation determined with NMR was similar to the milled sample (table 1, figure 3). There was a higher concentration of Brønsted acid sites probed by pyridine, but not in proportion to the higher $\mathrm{Al}$ content $\left(15 \mathrm{mmol} \mathrm{kg}-1\right.$ compared to $11 \mathrm{mmol} \mathrm{kg}^{-1}$, table 2). The thermal treatment also leads to a decrease of surface area and porosity (table 3 ), which is probably due to the introduced extraframework aluminum which can fill part of the pores and block access.

In an earlier publication, COK-14 was aluminated using atomic layer deposition (ALD) [28]. The zeolite platelets used in that study were larger, viz. $10 \mu \mathrm{m}$ x $10 \mu \mathrm{m}$ x $200 \mathrm{~nm}$ and the sample had a different texture, with larger micropore volume and higher specific surface area (table 3). For a similar aluminum incorporation as obtained here through milling (1.6 wt\%, table 1), a higher tetrahedral $\mathrm{Al}$ content was obtained ( $20 \%$ of the introduced $\mathrm{Al}$ ), but this did not give rise to higher Brønsted acidity, well on the contrary ( $6.5 \mathrm{mmol} \mathrm{kg}^{-1}$ by ALD compared to $11 \mathrm{mmol} \mathrm{kg}^{-1}$ with milling, table 2). Many explanations can be offered such as compensation of the framework charges by cationic extraframework $\mathrm{Al}$ species rather than protons or blockage of the access of pyridine to acid sites. The latter explanation is less probable, since ALD surprisingly increased the micropore volume and specific surface area (table 3 ).

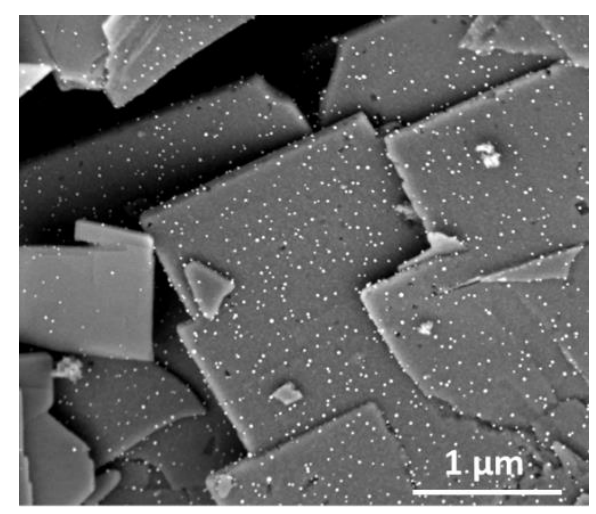

Figure 5: SEM image of COK-14-Mil loaded with $0.5 \mathrm{wt} \% \mathrm{Pt}$.

Impregnating the materials with $0.5 \mathrm{wt} \%$ Pt leads to an even distribution of well dispersed Pt particles over the external surface of the zeolite particles. Figure 5 shows a SEM image of such COK-14-Mil sample loaded with Pt. The white specks are Pt clusters of about $10 \mathrm{~nm}$ in diameter. This motivates again the application of milling to enhance the intimacy of the Pt particles and the acid sites inside the zeolite channels accessible via the edges of the flat crystals. 
Acid zeolite catalysts with highly dispersed noble metals can serve as bifunctional catalysts. They can isomerize and crack alkanes according to the mechanism fist suggested by Weisz [46] and Coonradt and Garwood [47]. Their behavior is the result of the synergy between the noble metal (Pt), which allows for dehydrogenation of alkanes and hydrogenation of alkenes, and the Brønsted acid sites, which protonate the alkenes into secondary alkylcarbenium ions, which can then be isomerized and cracked. The Weisz intimacy criterion indicates the need for intimacy between the acid sites and the noble metal sites [46]. The noble metal is not required to be on the zeolite phase [48] and could even be deposited on the binder of the zeolite powder used to prepare extrudates [46]. In ideal bifunctional catalysis, the rate limiting steps are the rearrangement and scission reactions of alkylcarbenium ion reaction intermediates [49].

The catalytic activity of COK-14(P), COK-14-Mil, -Therm and -ALD loaded with $0.5 \mathrm{wt} \% \mathrm{Pt}$ in the bifunctional conversion of $n$-decane was investigated. The catalytic activity was probed by increasing the temperature stepwise at constant space velocity. The zeolite samples were either used as such after the milling process, or subjected to an ammonium exchange. The ammonium exchange did not affect the crystallinity of the zeolites nor did it alter the specific surface area. But it altered the aluminum speciation probed with ${ }^{27} \mathrm{Al}$ MAS NMR (figure 6). In the milled sample, ammonium exchange enhanced the share of aluminum that is in a tetrahedral position (figure 6 , signal around $55 \mathrm{ppm}$ ), and the intensity of the signal of pentacoordinated aluminum (around $30 \mathrm{ppm}$ ) decreased. According to chemical analysis the overall aluminum content went down from 1.8 to $1.6 \mathrm{wt} \%$ during the ammonium exchange process. COK-14-Therm behaves differently. Here it is mainly the octahedral aluminum signal that decreased by ammonium exchange. The total aluminum content in this sample went down from 3.3 to $3.1 \mathrm{wt} \%$. Ammonium exchange is expected to remove cationic, non-framework aluminum species from the pores of the zeolite and is expected to enhance the acidity. Ammonium exchange after the milling enhanced the catalytic activity of both Pt/COK-14-Mil and Pt/COK-14-Therm (figure 7 a,b). Ammonium exchange has a positive effect on the activity of all three tested materials (figure $7 \mathrm{a}, \mathrm{b}, \mathrm{c}$ ). Therefore the results of the ammonium exchanged catalysts are discussed in more detail .
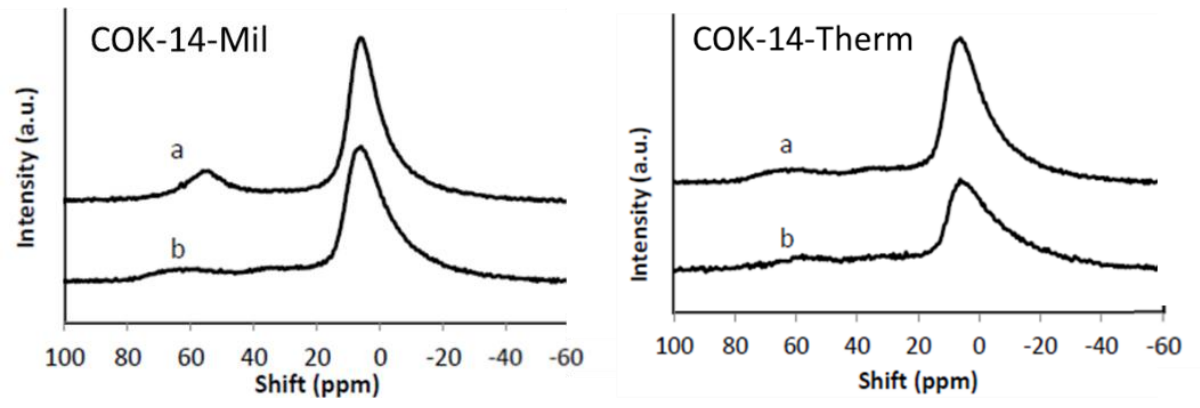

Figure 6: ${ }^{27} \mathrm{Al}$ MAS NMR spectra of -COK-14-Mil and COK-14-Therm after (a) and before (b) ammonium exchange. 

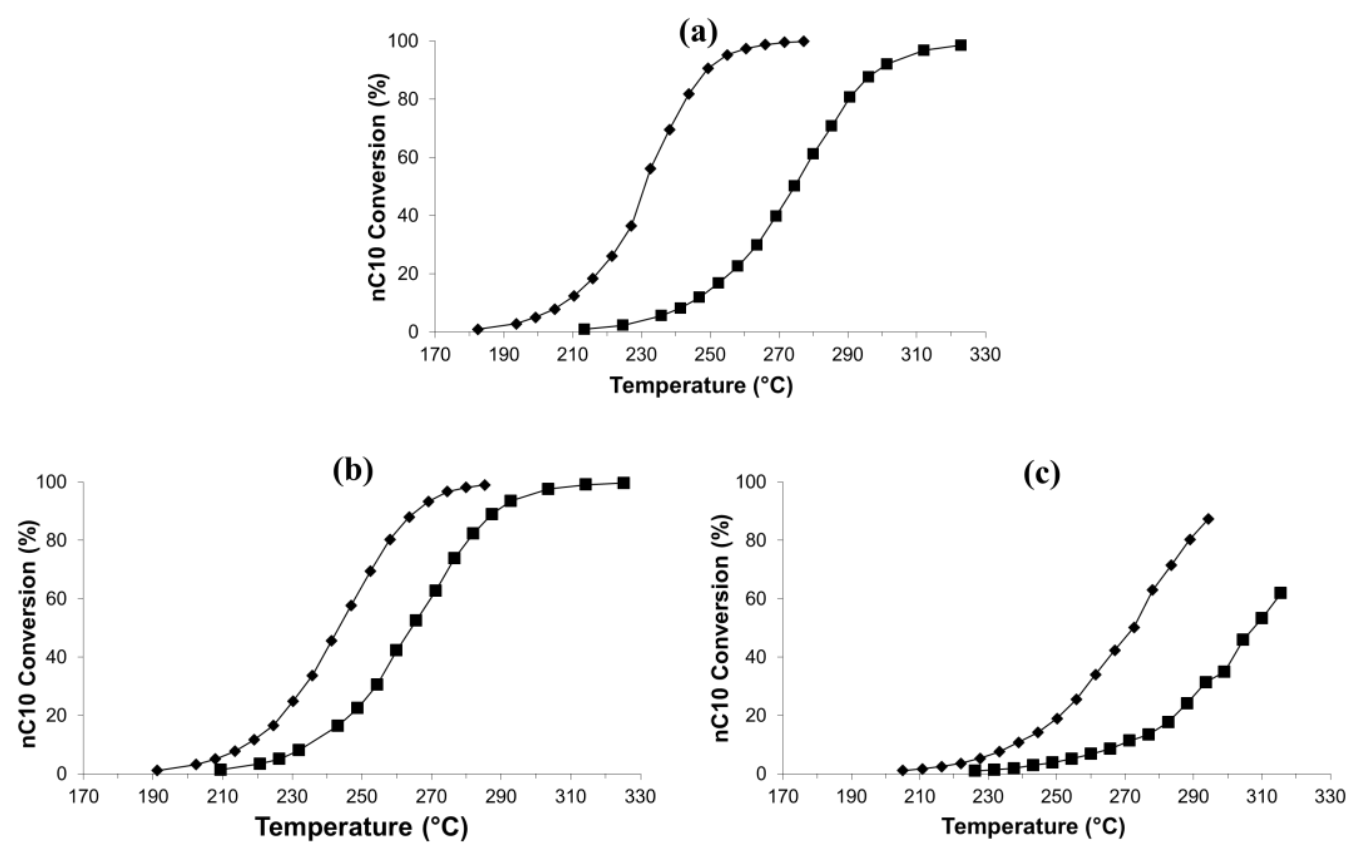

Figure 7: Conversion of n-decane plotted against reaction temperature after $(\downarrow)$ and before $(\bullet)$ ammonium exchange on Pt/COK-14-Mil (a), Pt/COK-14-Therm (b) and Pt/COK-14-ALD (c) (reaction conditions: $\mathrm{PH}_{2} / \mathrm{PC}_{10}=214$, W/F0 = 980 $\left.\mathrm{kg} \mathrm{s} \mathrm{mol}^{-1}, \mathrm{P}=0.45 \mathrm{MPa}\right)$.

For the parent zeolite and the three aluminated samples the conversion of $n$-decane is plotted against reaction temperature in figure $8 . \mathrm{Pt} / \mathrm{COK}-14$ was inactive because of the absence of aluminum and associated acid sites in the zeolite. Based on the position of the conversion curve on the temperature axis, Pt/COK-14-Mil was more active than Pt/COK-14-Therm and Pt/COK-14-ALD. The catalytic activity order does not reflect the Brønsted acidity, which is highest on the thermally aluminated sample (table 2). The apparent activation energy estimated from these data were $154,145,131 \mathrm{~kJ} \mathrm{~mol}^{-1}$, respectively. Hydrocracking has a high intrinsic activation energy [50]. The lower apparent activation energy of the samples Pt/COK-14-Therm and Pt/COK-14-ALD likely is due to diffusional limitation given the long diffusion paths of respectively 5 and $10 \mu \mathrm{m}$ inside the platelet crystals of unmilled COK-14 crystals.

In bifunctional catalytic conversion of an n-alkane, skeletal isomerization and hydrocracking are consecutive reactions. A high yield of skeletal isomers of the linear feed molecule is indicative of a good balance between the hydrogenation-dehydrogenation function provided by dispersed Pt metal particles, and the acid sites [45,49,51,52]. In this respect, Pt/COK-14-Mil also outperformed both other samples (figure 9). An extraordinary high yield of skeletal isomers of $72 \%$ was reached, which is unusual for a large pore zeolite. Ultrastable Y zeolites as comparison only reach ca. 55\% [50,53]. 


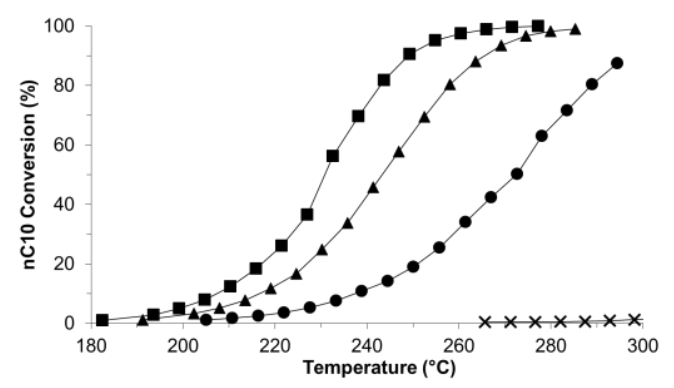

Figure 8: Conversion of n-decane plotted against reaction temperature on Pt/COK-14-Mil ( $\bullet$ ), Pt/COK-14-Therm ( $\triangle$ ), Pt/COK-14-ALD (•) and Pt/COK-14(P) (X) (reaction conditions: $\left.\mathrm{PH}_{2} / \mathrm{PC}_{10}=214, \mathrm{~W} / \mathrm{F} 0=980 \mathrm{~kg} \mathrm{~s} \mathrm{~mol}^{-1}, \mathrm{P}=0.45 \mathrm{MPa}\right)$.

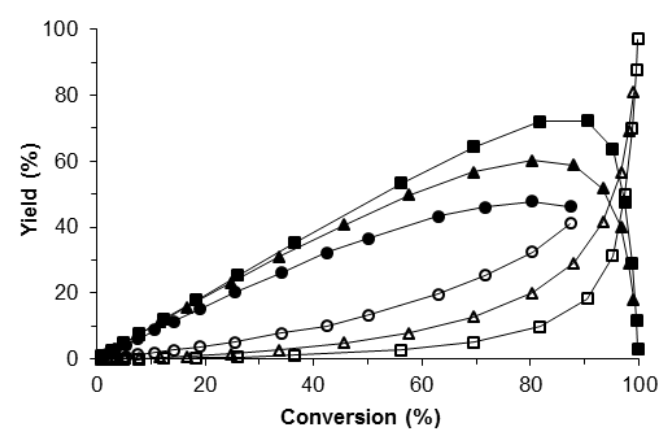

Figure 9: Yield of n-decane skeletal isomers (filled) and cracked products (empty) of Pt/COK-14-Mil (匹), Pt/COK-14Therm ( $\triangle$ ) and Pt/COK-14-ALD (•).

The higher $\mathrm{C}_{10}$ skeletal isomer yield on Pt/COK-14-Mil is likely due to the fragmentation of the COK14 particles, shortening of the diffusion path and the limiting secondary reaction being hydrocracking [51].

Branching isomerization of the $\mathrm{C}_{10}$ alkane chain is a stepwise process [53]. Monobranched isomers are the primary reaction products on the three catalysts (figure 10). The first side chain can be a methyl, an ethyl or a propyl group.

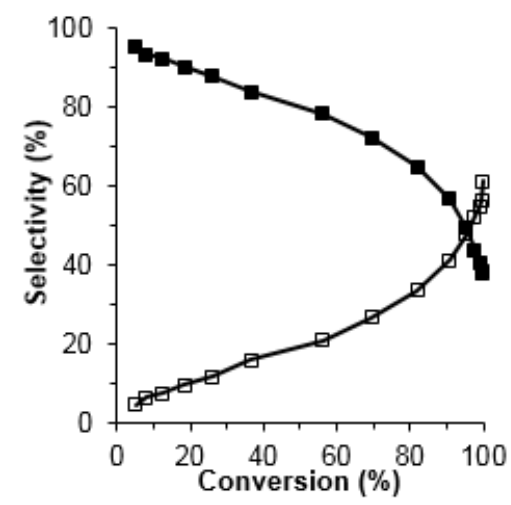

(a)

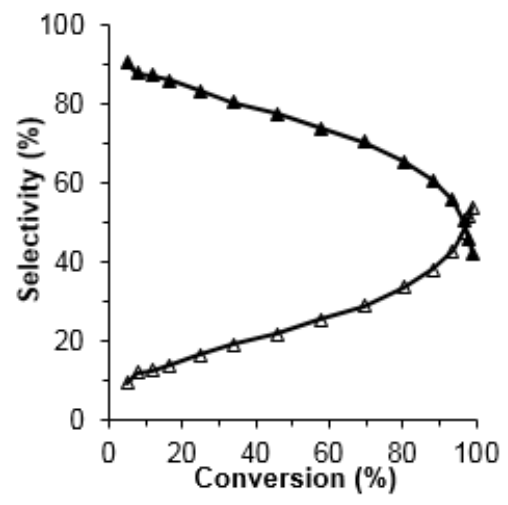

(b)

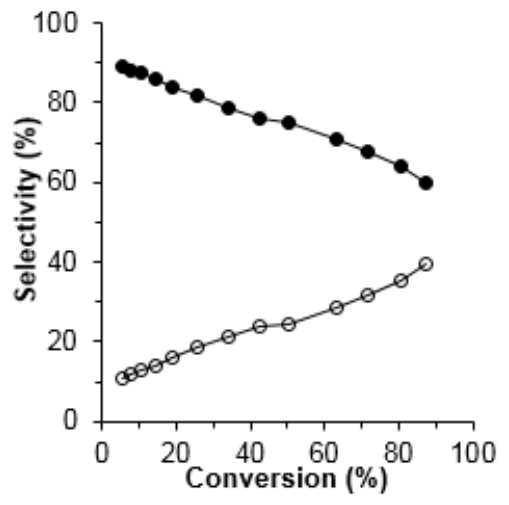

(c)

Figure 10: Distribution of $\mathrm{C}_{10}$ skeletal isomers obtained by hydroconversion on (a) Pt/COK-14-Mil, (b) Pt/COK-14Therm and (c) $\mathrm{Pt} / \mathrm{COK}-14-\mathrm{ALD}$. Monobranched $\mathrm{C}_{10}$ isomers (filled symbols) and dibranched $\mathrm{C}_{10}$ isomers (open symbols). 


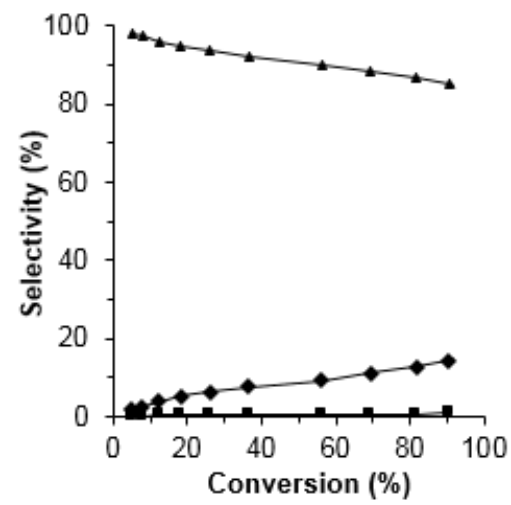

(a)

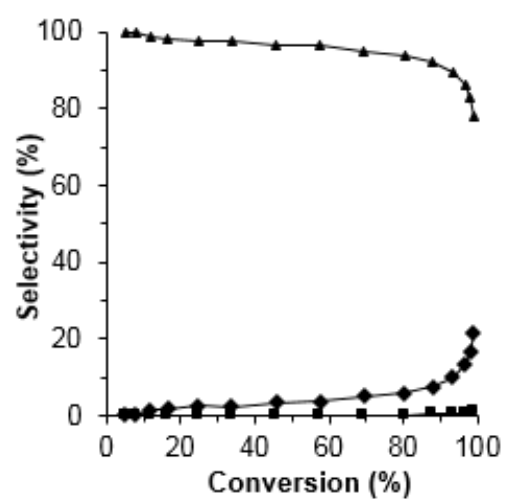

(b)

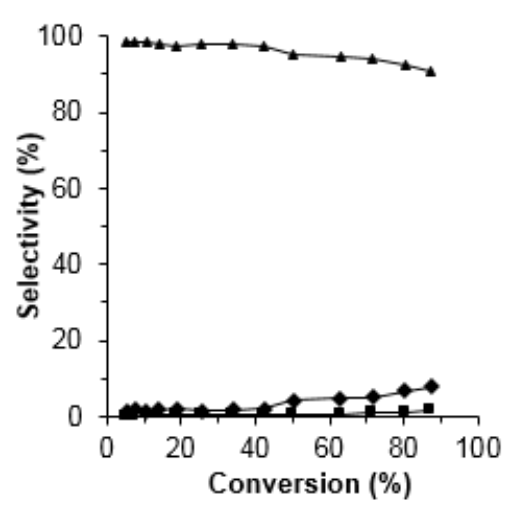

(c)

Figure 11: Distribution of monobranched skeletal isomers obtained from n-decane skeletal isomerization on (a) Pt/COK-14-Mil, (b) Pt/COK-14-Therm and (c) Pt/COK-14-ALD. Methylbranched ( $\Delta)$, ethylbranched ( $\bullet$ ) and propylbranched (ם).

Methylnonanes predominate. Ethyloctanes (3-ethyloctane and 4-ethyloctane) and 4-propylheptane are secondary products, which is surprising because a direct reaction pathway exists from n-decane by substituted protonated cyclobutyl and cyclopentyl type reaction intermediates [54]. On COK-14 apparently elongation of the side chain from methyl to ethyl and propyl is favored over direct formation (figure 11). Anyway, the formation of ethyloctanes suggests the catalysis is occurring in 12-MR pores being sufficiently wide $[42,45]$. 4-Propylheptane is the bulkiest $\mathrm{C}_{10}$ isomer. Its formation is sterically suppressed in 12-MR zeolites [42,45]

The evolution of the distribution of the methylnonanes is very similar for all three catalysts (figure 12). All catalysts show an initial preference for 3- and 4-methylnonane. The formation of 2-methylnonane is kinetically suppressed. This is explained by the branching mechanism via protonated cyclopropane reaction intermediates [55]. 5-Methylnonane is the least favored isomer. Like 2-methylnonane, its formation is also kinetically suppressed [54]. At thermodynamic equilibrium mixture it is least abundant of the four methylbranched isomers. Kinetic suppression of 2-methylnonane formation is typically observed in 12-MR zeolites where methylbranching is not influenced by steric effects. In 10-MR zeolites 2-methylnonane is the preferred isomer, especially when the branching of the linear molecules occurs preferentially in pore mouths $[56,57]$. The refined constraint index $\left(\mathrm{CI}^{*}\right)$, defined as the yield ratio of 2methylnonane to 5-methylnonane at 5\% conversion is convenient to distinguish among 10-MR and 12MR zeolites [42,45]. A CI* value between 1 and 2.5 indicates the presence of 12-MRs, while a higher value indicates the presence of 10-MRs [42,45]. The $\mathrm{CI}^{*}$ values of Pt/COK-14-Mil, Pt/COK-14-Therm and Pt/COK-14-ALD are 1.2, 1.3 and 1.6, suggesting again that the catalytic activity is concentrated in the 12-MR channels. The selective activation of the 12-MR pores over the 10-MR pores may be due to the alumination procedure in which a voluminous precursor such as aluminum isopropoxide is used. This may be adsorbed and react preferentially in the wider pores. 


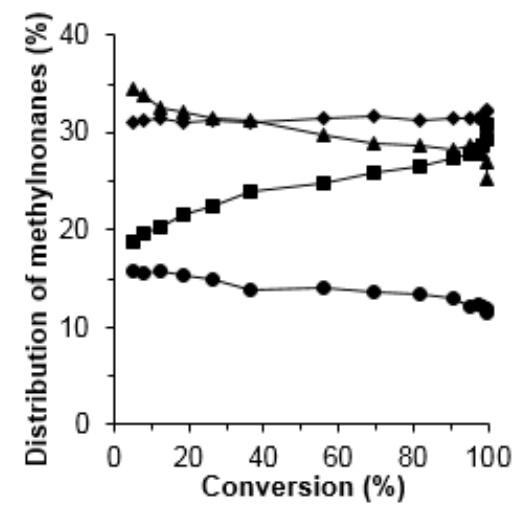

(a)

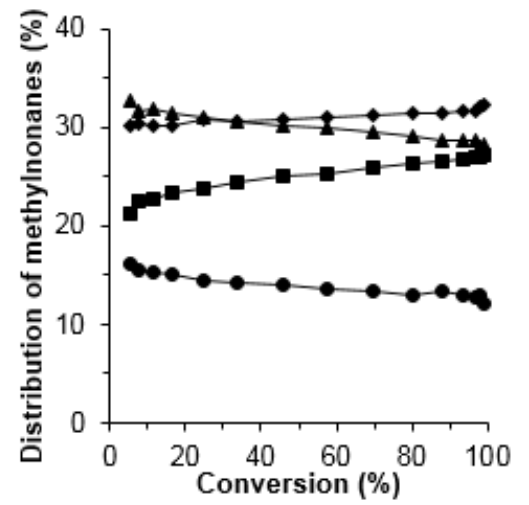

(b)

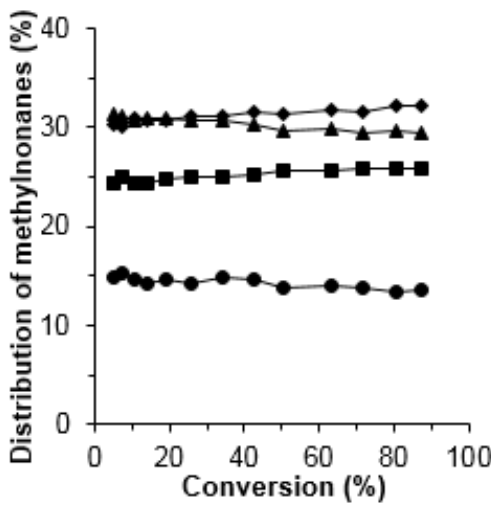

(c)

Figure 12: Distribution of methylnonane skeletal isomers obtained from hydrocracking on (a) Pt/COK-14-Mil, (b) Pt/COK-14-Therm and (c) Pt/COK-14-ALD: 2-methylnonane (a), 3-methylnonane ( $\bullet)$, 4-methylnonane ( $\Delta$ ), 5-methylnonane $(\bullet)$.

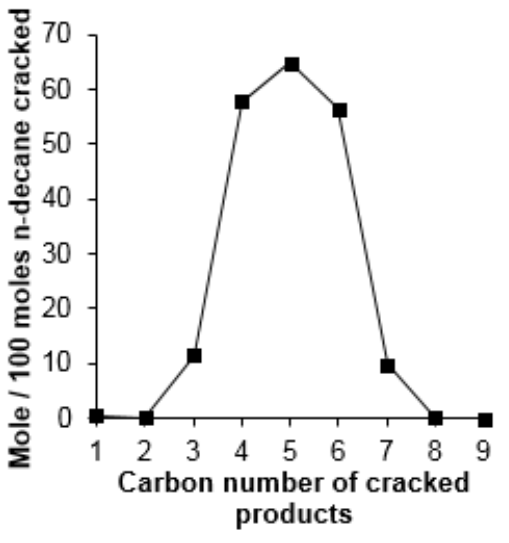

(a)

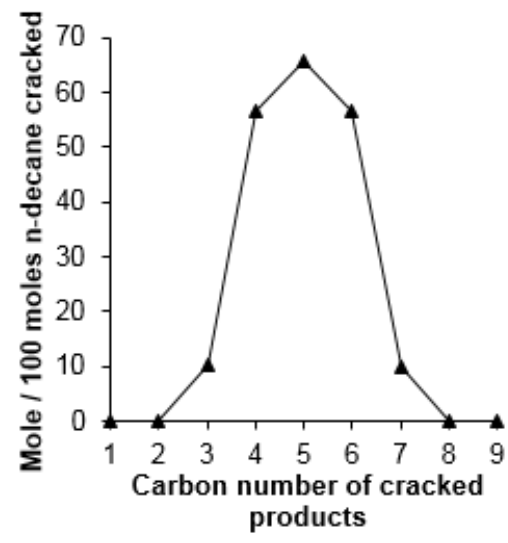

(b)

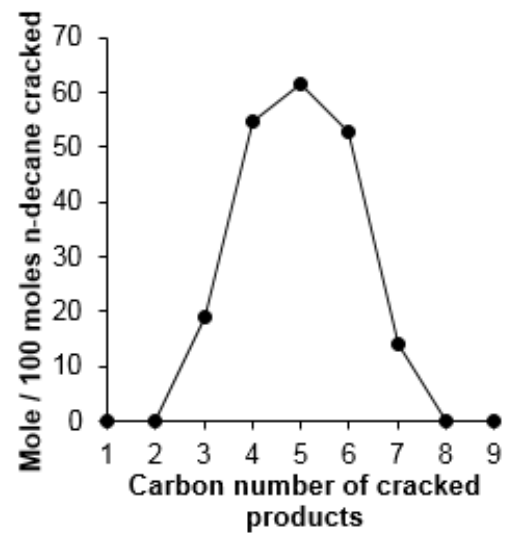

(c)

Figure 13: Molar yields of cracked products at $35 \%$ hydrocracking yield, expressed per 100 moles of n-decane cracked (a) Pt/COK-14-Mil, (b) Pt/COK-14-Therm and (c) Pt/COK-14-ALD.

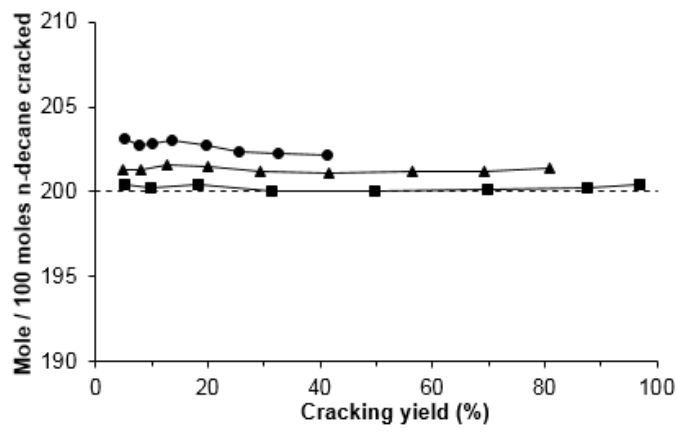

Figure 14: Mole cracked products formed per 100 moles of n-decane cracked on Pt/COK-14-Mil (匹), Pt/COK-14-Therm $(\triangle)$ and Pt/COK-14-ALD (•).

The yield of cracked product fractions at $35 \%$ hydrocracking yield is presented in figure 13 . The $\mathrm{C}_{10}$ molecule can be cracked in two $\mathrm{C}_{5}$ fragments, or $\mathrm{C}_{4}$ plus $\mathrm{C}_{6}$ or $\mathrm{C}_{3}$ and $\mathrm{C}_{7}$. Central cracking prevails, followed by $\mathrm{C}_{4}$ plus $\mathrm{C}_{6}$ formation. Scission into $\mathrm{C}_{3}$ and $\mathrm{C}_{7}$ fragments is less favored. This distribution reflects the stability of the alkylcarbenium ions involved in the rival $\beta$-scission pathways [55]. The molar yield of cracked products per 100 mol of feed cracked is plotted against the cracking yield in figure 14 . 
Primary cracking results in formation of 200 mol cracked products out of $100 \mathrm{~mol}$ feed molecules. If primary fragments are cracked a second time, the molar yield of cracked products is higher, and exceeds $200 \mathrm{~mol}$ per $100 \mathrm{~mol}$ cracked $\mathrm{C}_{10}$. Pt/COK-14-Mil displays primary cracking over the entire conversion range. Some secondary cracking occurs on Pt/COK-14-Therm whereas Pt/COK-14-ALD shows most secondary cracking of the three tested catalysts. Secondary cracking is manifested when the diffusion path along acid sites is long [51]. The milling process suppressed secondary cracking by shortening these diffusion paths.

The composition of the $\mathrm{C}_{4}$ fraction (figure 15), $\mathrm{C}_{5}$ fraction (figure 16) and $\mathrm{C}_{6}$ fraction (figure 17) obtained on the different catalysts is quite similar. Branched isomers prevail in these fractions. It confirms the feed molecules undergo substantial branching before being scissioned [55].

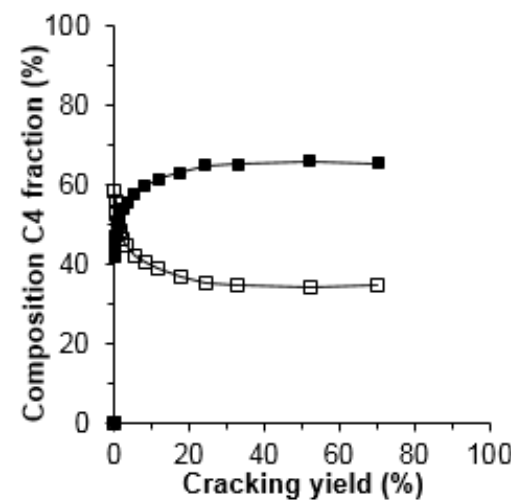

(a)

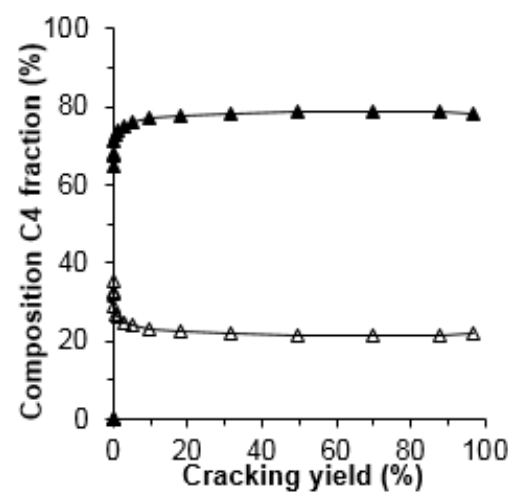

(b)

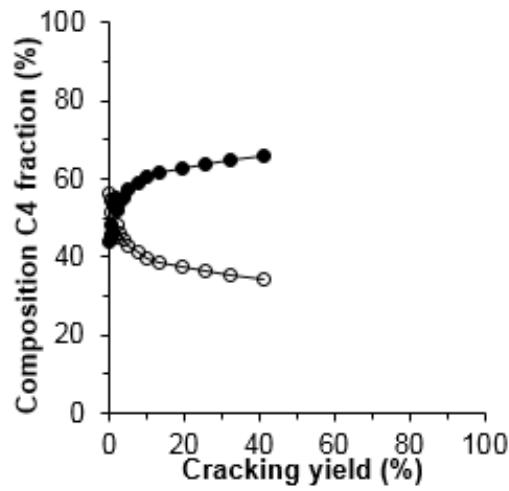

(c)

Figure 15: Composition of the $\mathrm{C}_{4}$ fraction of the cracked products against the hydrocracking yield on (a) $\mathrm{Pt} / \mathrm{COK}-14$ Mil, (b) Pt/COK-14-Therm and (c) Pt/COK-14-ALD. Branched isomers (filled symbols) and n-C4 (open symbols).

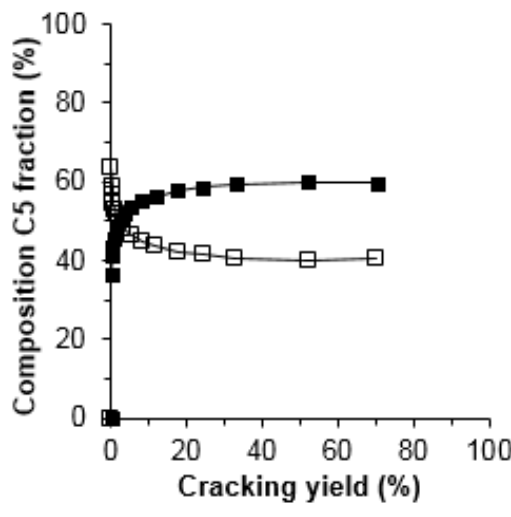

(a)

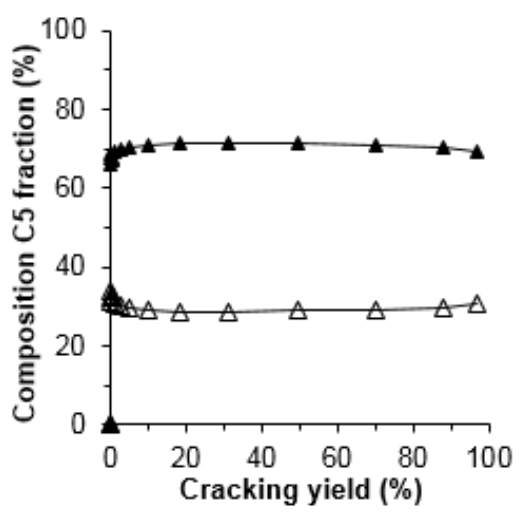

(b)

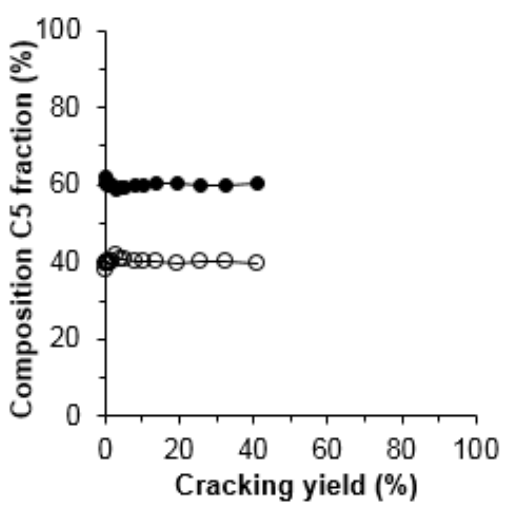

(c)

Figure 16: Composition of the $\mathrm{C}_{5}$ fraction of the cracked products against the hydrocracking yield for (a) $\mathrm{Pt} / \mathrm{COK}$-14Mil, (b) Pt/COK-14-Therm and (c) Pt/COK-14-ALD. Branched isomers (filled symbols) and n-C5 (open symbols). 


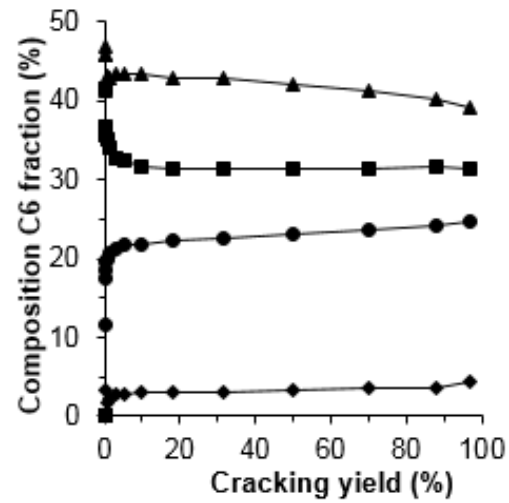

(a)

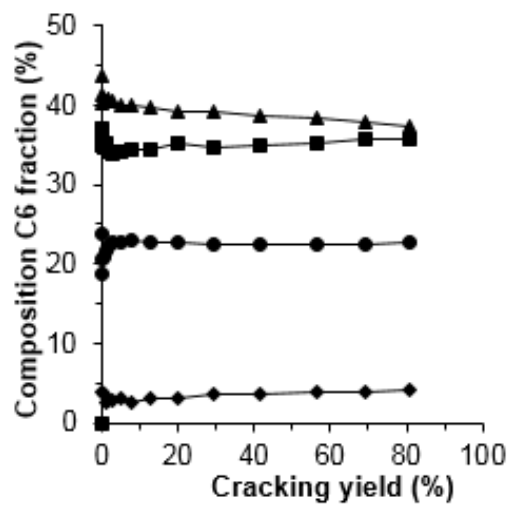

(b)

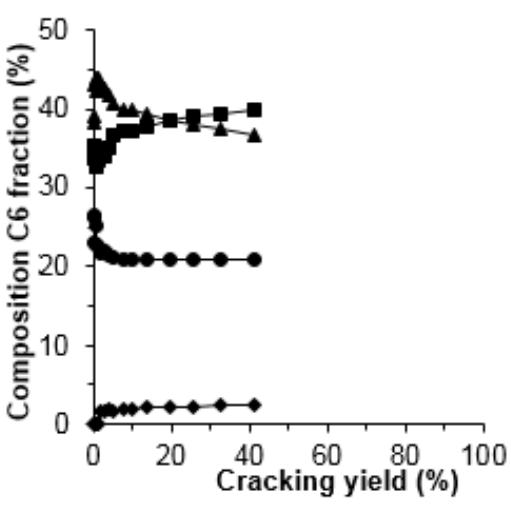

(c)

Figure 17: Composition of the $\mathrm{C}_{6}$ fraction of the cracked products against the hydrocracking yield for (a) Pt/COK-14-

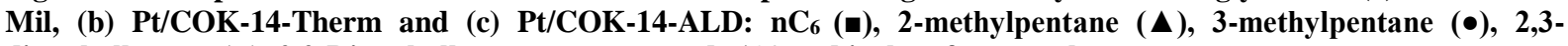
dimethylbutane $(\diamond)$. 2,2-Dimethylbutane never exceeds $1 \%$ and is therefore not shown.

\section{Conclusions}

All silica -COK-14 zeolite was successfully aluminated via wet ball milling in presence of aluminum isopropoxide on a multidirectional mixer. The milling resulted in incorporation of tetrahedrally coordinated aluminum in the framework, which gave rise to Brønsted acidity and acid catalytic activity. After an ammonium exchange, impregnation with Pt and calcination, a bifunctional zeolite catalyst was obtained which behaved like a 12-MR zeolite in the bifunctional conversion of n-decane. The aluminated zeolite did not present any 10-MR pore characteristics. The selective introduction of acid sites in the 12-MR pores could be due to the voluminous nature of the alumination agent, aluminum isopropoxide, adsorbing preferentially in the wider pores. Although the degree of alumination was quite low, corresponding to a framework $\mathrm{Si} / \mathrm{Al}$ ratio estimated at 1,500 (as determined by pyridine adsorption tests), ideal bifunctional catalysis was obtained, with high yields of feed isomers (up to 72\%), and pure primary cracking up to high conversion levels. The shortening of the diffusion path by fragmentation of the zeolite platelets by ball milling offers an explanation. For comparison, thermal alumination of the unmilled samples using the same aluminating agent, or using atomic layer deposition leads to catalysts with more pronounced secondary reactions. Wet ball milling in presence of a liquid containing an $\mathrm{Al}$ precursor is revealed to be an attractive approach for catalytic functionalization of all-silica zeolites. Many more zeolites may be catalytically activated using this technique, and other chemical elements beside aluminum may be introduced.

\section{Acknowledgments}

JAM acknowledges the Flemish government for long-term structural funding (Methusalem). Kristof Houthoofd is acknowledged for performing the ${ }^{27} \mathrm{Al}$ MAS NMR experiments and Wout Veulemans for his assistance in using the Turbula equipment. 


\section{References}

[1] P.A. Barrett, T. Boix, M. Puche, D.H. Olson, E. Jordan, H. Koller, M.A. Camblor, ITQ-12: a new microporous silica polymorph potentially useful for light hydrocarbon separations, Chem. Commun. (2003) 2114-2115.

[2] C.E.A. Kirschhock, M. De Prins, E. Verheyen, A. Ryzhikov, T. Jean Daou, H. Nouali, F. Taulelle, J.A. Martens, J. Patarin, Intrusion-extrusion spring performance of -COK-14 zeolite enhanced by structural changes, Phys. Chem. Chem. Phys. 18 (2016) 18795-18801.

[3] Z. Wang, H. Wang, A. Mitra, L. Huang, Y. Yan, Pure-silica zeolite low-k dielectric thin films, Adv. Mater. 13 (2001) 746.

[4] W. Vermeiren, J.P. Gilson, Impact of zeolites on the petroleum and petrochemical industry, Top. Catal. 52 (2009) 1131-1161.

[5] J. Weitkamp, L. Puppe, Catalysis and Zeolites: Fundamentals and Applications, 1999.

[6] http://www.iza-online.org, IZA website. http://www.iza-online.org/ (accessed October 31, 2017).

[7] X. Shijing, C. Shimian, L. Huanqin, Z. Shuqing, Z. Lirong, An investigation of supported catalysts for propylene polymerization I. influences of milling and heat-treatment in vacuum on the structure and characteristics of the catalysts, Chin. J. Catal. 4 (1980).

[8] U. Kamolphop, S.F.R. Taylor, J.P. Breen, R. Burch, J.J. Delgado, S. Chansai, C. Hardacre, S. Hengrasmee, S.L. James, Low-temperature selective catalytic reduction (SCR) of NOx with noctane using solvent-free mechanochemically prepared Ag/Al2O3 catalysts, ACS Catal. 1 (2011) $1257-1262$.

[9] A. Düvel, E. Romanova, M. Sharifi, D. Freude, M. Wark, P. Heitjans, M. Wilkening, Mechanically induced phase transformation of $\gamma$-A12O3 into $\alpha$-Al2O3. Access to structurally disordered $\gamma$-Al2O3 with a controllable amount of pentacoordinated $\mathrm{Al}$ sites, J. Phys. Chem. C. 115 (2011) 22770-22780.

[10] P. Baláž, Mechanochemistry in nanoscience and minerals engineering, 2008.

[11] P. Baláž, M. Achimovičová, M. Baláž, P. Billik, Z. Cherkezova-Zheleva, J.M. Criado, F. Delogu, E. Dutková, E. Gaffet, F.J. Gotor, R. Kumar, I. Mitov, T. Rojac, M. Senna, A. Streletskii, K. Wieczorek-Ciurowa, Hallmarks of mechanochemistry: from nanoparticles to technology, Chem. Soc. Rev. 42 (2013) 7571.

[12] K. Ralphs, C. Hardacre, S.L. James, Application of heterogeneous catalysts prepared by mechanochemical synthesis, Chem. Soc. Rev. 42 (2013) 7701-7718.

[13] T. Kurniawan, O. Muraza, K. Miyake, A.S. Hakeem, Y. Hirota, A.M. Al-Amer, N. Nishiyama, Conversion of dimethyl ether to olefins over nanosized mordenite fabricated by a combined highenergy ball milling with recrystallization, Ind. Eng. Chem. Res. 56 (2017) 4258-4266.

[14] K. Akçay, A. Sirkecioğlu, M. Tatlier, Ö.T. Savaşçi, A. Erdem-Şenatalar, Wet ball milling of 
zeolite HY, Powder Technol. 142 (2004) 121-128.

[15] K. Wieczorek-Ciurowa, K. Gamrat, Some aspects of mechanochemical reactions, Mater. Sci. Pol. 25 (2007) 219.

[16] K. Wieczorek-Ciurowa, J. Rakoczy, A. Błońska-Tabero, E. Filipek, J. Nizioł, P. Dulian, Mechanochemical synthesis of double vanadate in $\mathrm{Cu}-\mathrm{Fe}-\mathrm{V}-\mathrm{O}$ system and its physicochemical and catalytic properties, in: Catal. Today, 2011: pp. 314-317.

[17] C. Kosanović, J. Bronić, B. Subotić, I. Smit, M. Stubičar, A. Tonejc, T. Yamamoto, Mechanochemistry of zeolites: Part 1. Amorphization of zeolites A and X and synthetic mordenite by ball milling, Zeolites. 13 (1993) 261-268.

[18] A.Y. Buzimov, S.N. Kulkov, W. Eckl, S. Pappert, L.A. Gömze, E. Kurovics, I. Kocserha, R. Géber, Effect of mechanical treatment on properties of zeolites with chabazite structure, J. Phys. Conf.Series. 790 (2017).

[19] J. Xie, S. Kaliaguine, Zeolite ball milling as a means of enhancing the selectivity for base catalyzed reactions, Appl. Catal. A, Gen. 148 (1997) 415-426.

[20] T. Wakihara, R. Ichikawa, J. Tatami, K. Komeya, T. Meguro, Ion-exchange properties of nano zeolite A prepared by bead milling and post-milling recrystallization method, in: T. Ohji, M. Singh, M. Halbig, S. Mathur (Eds.), Adv. Process. Manuf. Technol. Struct. Multifunct. Mater. VI, The American Ceramic Society, 2012: pp. 129-134.

[21] G. Mucsi, K. Bohacs, Wet grinding of zeolite in stirred media mill, IOP Conf. Ser. Mater. Sci. Eng. 123 (2016).

[22] A. Charkhi, H. Kazemian, M. Kazemeini, Optimized experimental design for natural clinoptilolite zeolite ball milling to produce nano powders, Powder Technol. 203 (2010) 389396.

[23] Z. Yang, Y. Liu, C. Yu, X. Gu, N. Xu, Ball-milled NaA zeolite seeds with submicron size for growth of NaA zeolite membranes, J. Memb. Sci. 392-393 (2012) 18-28.

[24] D. Panda, E.A. Kumar, Surface modification of zeolite 4A molecular sieve by planetary ball milling, in: Mater. Today Proc., 2017: pp. 395-404.

[25] L.E. Burris, M.C.G. Juenger, Milling as a pretreatment method for increasing the reactivity of natural zeolites for use as supplementary cementitious materials, Cem. Concr. Compos. 65 (2016).

[26] S.P. Sree, J. Dendooven, T.I. Korányi, G. Vanbutsele, K. Houthoofd, D. Deduytsche, C. Detavernier, J.A. Martens, Aluminium atomic layer deposition applied to mesoporous zeolites for acid catalytic activity enhancement, Catal. Sci. Technol. 1 (2011) 218.

[27] C. Detavernier, J. Dendooven, S.P. Sree, K.F. Ludwig, J.A. Martens, Tailoring nanoporous materials by atomic layer deposition., Chem. Soc. Rev. 40 (2011) 5242-5253.

[28] E. Verheyen, S. Pulinthanathu Sree, K. Thomas, J. Dendooven, M. De Prins, G. Vanbutsele, E. Breynaert, J.-P. Gilson, C.E.A. Kirschhock, C. Detavernier, J.A. Martens, Catalytic activation of 
OKO zeolite with intersecting pores of 10- and 12-membered rings using atomic layer deposition of aluminium, Chem. Commun. 50 (2014) 4610-4612.

[29] A. Corma, C. Corell, F. Llopis, A. Martínez, J. Pérez-Pariente, Proposed pore volume topology of zeolite MCM-22 based on catalytic tests, Appl. Catal. A, Gen. 115 (1994) 121-134.

[30] S.B.C. Pergher, A. Corma, V. Fornes, Preparation and characterization of MCM-22 zeolite and its layered precursor, Quim. Nova. 26 (2003) 795-802.

[31] W. Souverijns, W. Verrelst, G. Vanbutsele, J.A. Martens, P.A. Jacobs, Micropore structure of zeolite MCM-22 as determined by the decane catalytic test reaction, J. Chem. Soc. Chem. Commun. (1994) 1671-1672.

[32] B. Tijsebaert, M. Henry, H. Gies, F.S. Xiao, W. Zhang, X. Bao, H. Imai, T. Tatsumi, U. Müller, B. Yilmaz, P. Jacobs, D. De Vos, Exploring the void structure and activity of RUB-39 based expanded materials using the hydroconversion of decane, J. Catal. 282 (2011) 47-53.

[33] P.B. Weisz, Molecular shape selective catalysis, Pure Appl. Chem. 52 (1980) 2091-2103.

[34] S.M. Csicsery, Catalysis by shape selective zeolites - science and technology, Pure Appl. Chem. 58 (1986) 841-856.

[35] T. Yashima, K. Yamagishi, S. Namba, S. Nakata, S. Asaoka, Alumination of ZSM-5 type zeolite with AlCl3, in: Stud. Surf. Sci. Catal., 1988: pp. 175-182.

[36] J. Ma, Y. Kang, N. Ma, W. Hao, Y. Wang, R. Li, A high acid mesoporous USY zeolite prepared by alumination, Mater. Sci. Pol. 31 (2013) 19.

[37] E. Verheyen, L. Joos, K. Van Havenbergh, E. Breynaert, N. Kasian, E. Gobechiya, K. Houthoofd, C. Martineau, M. Hinterstein, F. Taulelle, V. Van Speybroeck, M. Waroquier, S. Bals, G. Van Tendeloo, C.E.A. Kirschhock, J.A. Martens, Design of zeolite by inverse sigma transformation, Nat. Mater. (2012).

[38] O. V. Shvets, A. Zukal, N. Kasian, N. Žilková, J. Čejka, The role of crystallization parameters for the synthesis of germanosilicate with UTL topology, Chem. - A Eur. J. 14 (2008) 1013410140.

[39] P. Schatz, Rhythmusforschung und Technik, Freies Geistesleken, 1975.

[40] J. Musschoot, Q. Xie, D. Deduytsche, S. den Berghe, R.L. Van Meirhaeghe, C. Detavernier, Atomic layer deposition of titanium nitride from \{TDMAT\} precursor, Microelectron. Eng. 86 (2009) 72-77.

[41] N. Kasian, T.I. Koranyi, G. Vanbutsele, K. Houthoofd, J.A. Martens, C.E.A. Kirschhock, Decane hydroisomerization test probing catalytic activity and selectivity of aluminum and boron substituted extra-large pore UTL zeolite, in: Top. Catal., 2010: pp. 1374-1380.

[42] J.A. Martens, M. Tielen, P.A. Jacobs, J. Weitkamp, Estimation of the void structure and pore dimensions of molecular sieve zeolites using the hydroconversion of n-decane, Zeolites. 4 (1984) 98-107.

[43] W. Huybrechts, J. érôme Mijoin, P.A. Jacobs, J.A. Martens, Development of a fixed-bed 
continuous-flow high-throughput reactor for long-chain n-alkane hydroconversion, Appl. Catal. A Gen. 243 (2003) 1-13.

[44] E. Verheyen, L. Joos, C. Martineau, C.J. Dawson, C. Weidenthaler, W. Schmidt, R. Yuan, E. Breynaert, V. Van Speybroeck, M. Waroquier, F. Taulelle, M.M.J. Treacy, J.A. Martens, C.E.A. Kirschhock, Flexibility versus rigidity: what determines the stability of zeolite frameworks? A case study, Mater. Horizons. 1 (2014) 582-587.

[45] J.A. Martens, P.A. Jacobs, The potential and limitations of the n-decane hydroconversion as a test reaction for characterization of the void space of molecular sieve zeolites, Zeolites. 6 (1986) 334-348.

[46] P.B. Weisz, Polyfunctional Heterogeneous Catalysis, in: D.D. Eley, P.W. Selwood, P.B. Weisz, A.A. Balandin, J.H. De Boer, P.J. Debye, P.H. Emmett, J. Horiuti, W. Jost, G. Natta, E.K. Rideal, H.S. Taylor (Eds.), Adv. Catal., 13th ed., Academic Press, 1962: pp. 137-190.

[47] H.L. Coonradt, W.E. Garwood, Mechanism of hydrocracking. Reactions of paraffins and olefins, Ind. Eng. Chem. Process Des. Dev. 3 (1964) 38-45.

[48] R. Parton, L. Uytterhoeven, J.A. Martens, P.A. Jacobs, G.F. Froment, Synergism of ZSM-22 and Y zeolites in the bifunctional conversion of n-alkanes, Appl. Catal. 76 (1991) 131-142.

[49] J. Weitkamp, Catalytic hydrocracking-mechanisms and versatility of the process, ChemCatChem. (2012).

[50] J. Zecevic, G. Vanbutsele, K.P. De Jong, J.A. Martens, Nanoscale intimacy in bifunctional catalysts for selective conversion of hydrocarbons, Nature. (2015).

[51] M. Guisnet, “ideal” bifunctional catalysis over Pt-acid zeolites, Catal. Today. (2013).

[52] M. Guisnet, F. Alvarez, G. Giannetto, G. Perot, Hydroisomerization and hydrocracking of nheptane on Pth zeolites. Effect of the porosity and of the distribution of metallic and acid sites., Catal. Today. 1 (1987) 415-433.

[53] J.A. Martens, R. Parton, L. Uytterhoeven, P.A. Jacobs, G.F. Froment, Selective conversion of decane into branched isomers, Appl. Catal. (1991).

[54] J.A. Martens, P.A. Jacobs, Evidence for branching of long-chain n-alkanes via protonated cycloalkanes larger than cyclopropane, J. Catal. (1990).

[55] J. Weitkamp, P.A. Jacobs, J.A. Martens, Isomerization and hydrocracking of C9 through C16 nalkanes on Pt/HZSM-5 zeolite, Appl. Catal. (1983).

[56] J.A. Martens, G. Vanbutsele, P.A. Jacobs, J. Denayer, R. Ocakoglu, G. Baron, J.A. Muñoz Arroyo, J. Thybaut, G.B. Marin, Evidences for pore mouth and key-lock catalysis in hydroisomerization of long n-alkanes over 10-ring tubular pore bifunctional zeolites, Catal. Today. (2001).

[57] W. Souverijns, J.A. Martens, G.F. Froment, P.A. Jacobs, Hydrocracking of isoheptadecanes on Pt/H-ZSM-22: An example of pore mouth catalysis, J. Catal. (1998). 